\section{Relationship between the Decrease in Urinary Excretion of Histamine and the Initiation of the Labour Process}

As has been shown by Kahlson et al., in rats fed on a histamine-free diet, the urinary excretion of histamine begins at about the fifteenth day of pregnancy and increases rapidly. The peak value occurs 1 or 2 days before birth, then falls steeply to the pre-pregnant level. The increase in histamine excretion depends on the number of young in the litter; the larger the number, the greater the increase in histamine excretion ${ }^{1}$.

Investigations were made to demonstrate the relationship between the decrease in histamine excretion and the initiation of the labour process. Observations were made on white laboratory rats, fed on a normal diet. The method described in detail by McIntire, Roth and Shaw ${ }^{2}$ was adapted to measure the amount of histamine in urine.

Table 1. Mean DaILY ExcRetion on Histayine ( $\mu \mathrm{GM}$. )

\begin{tabular}{|lc|c|cc|}
\hline & & Control animals & \multicolumn{2}{|c|}{ Experimental } \\
\hline Before pregnancy & & 50 & 50 \\
Days after mating & 15 & 120 & 130 & \\
& 20 & 880 & 750 & \\
& 21 & 104 & 700 \\
& 22 & 60 & 750 & Administration \\
& 23 & - & 200 & of histamine \\
& 24 & - & 60 & \\
& 25 & - & 100 \\
& & & \\
\hline
\end{tabular}

Two days before the time of the expected parturition, that is, just before the onset of the period of low histamine excretion, $1.5 \mathrm{mgm}$. of histamine hydrochloride daily, in three doses, was injected subcutaneously during light ether anæsthesia. In this way the pretermal decrement in urinary histamine was prevented, and the high daily excretion (500-850 $\mu \mathrm{gm}$. was maintained artificially for two days.

It has been observed that, after the last injection of histamine, urinary excretion fell gradually during 1.5-2 days to about the pre-pregnant level. The labour process began about $30 \mathrm{hr}$. after decrease of the histamine-level. In this way the pregnancy was prolonged for two days. Some of the young in the litter from such a prolonged pregnancy were born dead; others showed after-birth weak respiratory movements, and died soon afterwards.

HatrNa WiskonT-BuCzKowska

Department of Physiology,

Medical Academy Gdańsk,

$$
\text { Poland. }
$$

${ }^{1}$ Kahlson, G., Rosengren, Elsa, and Westling, H., J. Physiol., 143, 91 (1958).

${ }^{2}$ MeIntire, Floyd C., Roth, L. W., and Shaw, J. L., J. Biol. Chem. 170, 537 (1947).

\section{RADIOBIOLOGY}

\section{Estimation of Time of Generation of Living Cells}

THE use of tritiated thymidine as a labelling agent has greatly facilitated examination of nuclear reproduction and cellular proliferation ${ }^{1-4}$. In such work, it has been customary to focus attention on the proliferation and fate of the cells that are labelled. Mendelsohn, however, has studied the fate of both labelled and unlabelled cells in tumours of mice and has used data obtained from both the labelled and unlabelled cell populations to derive the ratio of proliferative cells to total cells (the growth fraction) $)^{5,6}$. In the method

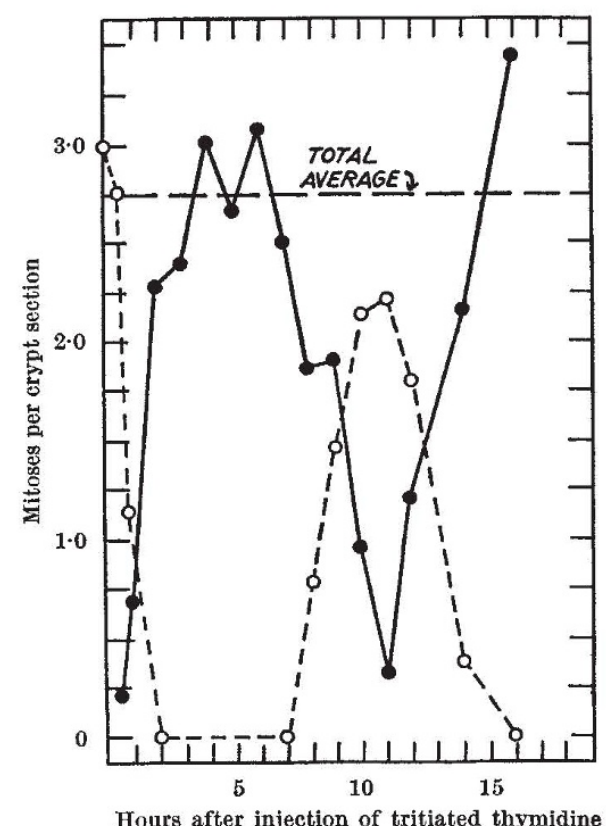

Fig. 1. Number of mitotic flgures per crypt section as a function of time after injection of tritiated thymidine: dashed curve, unlabelled figures; solid line, labelled figures. Total average represents the totai number of mitotic figures per crypt section

presented here, applicable whenever a cohort of cells (that is, a fraction of the population) is labelled, the data for the labelled and unlabelled cells are analysed separately. In this way more information is obtained than when either only the labelled cells are studied or when data for the two cell populations are combined. The generation time of both labelled and unlabelled cells can be determined and compared, thus providing a method by which one aspect of toxicity of tritiated thymidine can be examined.

The following experiment illustrates the use of this method in the determination of generation time and mitotic time of the labelled cells, and generation time of the unlabelled cells. $C A F_{1}$ mice, 93 days old, (weighing $25 \mathrm{gm}$.) received intraperitoneally $50 \mu \mathrm{c}$. of tritiated thymidine $(360 \mathrm{mc} / \mathrm{mM})$. Thereafter at intervals up to $16 \mathrm{hr} ., 1$ or 2 animals were killed to obtain samples of the duodenum. Autoradiographs were made $e^{7}$ of $3 \mu$ duodenal sections pre-stained by the Feulgen reaction. For each time of killing, the numbers of labelled and unlabelled mitotic figures (all stages) were counted in about 20 crypts of Lieberkühn (about 1,000 cells). The mean numbers of labelled $\left(M_{1}\right)$ and unlabelled $\left(M_{u}\right)$ mitotic figures per crypt section were calculated from these data and plotted as a function of time (Fig. 1).

Generation Time. In the case of the unlabelled cohort, the curve traced by $M_{u}$ began at $3 \cdot 0$ mitoses per crypt section; at $2 \mathrm{hr}$. after injection the value was zero; the value began to increase again at 7 hr., and a peak value of $2 \cdot 2$ was reached at $11 \mathrm{hr}$. Thus a cycle was completed in $11 \mathrm{hr}$., which is an estimate of the generation time. If the duration had been measured between similar points (in the range $\left.M_{u}=1 \cdot 5-0 \cdot 5\right)$ on the descending limbs of two successive cycles, it would have been about $12 \mathrm{hr}$. We therefore took the generation time to be $11.5 \mathrm{hr}$.

In the case of the labelled cohort, the curve traced by $M_{L}$ began at zero and after passing through a peak of about 3 mitoses per crypt section (in agreement 